\title{
Pharmacokinetics of Etravirine Combined with Atazanavir/Ritonavir and a Nucleoside Reverse Transcriptase Inhibitor in Antiretroviral Treatment-Experienced, HIV-1-Infected Patients
}

\author{
Catherine Orrell, ${ }^{1}$ Franco Felizarta, ${ }^{2}$ André Nell, ${ }^{3}$ Thomas N. Kakuda, ${ }^{4}$ Ludo Lavreys, ${ }^{5}$ \\ Steven Nijs, ${ }^{5}$ Lotke Tambuyzer, ${ }^{5}$ Rodica Van Solingen-Ristea, ${ }^{4}$ and Frank L. Tomaka ${ }^{4}$ \\ ${ }^{1}$ Desmond Tutu HIV Foundation, UCT Medical School, P.O. Box 13801, Mowbray, Cape Town 7705, South Africa \\ ${ }^{2}$ Private Practice, 3535 San Dimas Street, Suite 24, Bakersfield, CA 93301, USA \\ ${ }^{3}$ Parexel International, University of the Free State, Campus Avenue South, Bloemfontein, Free State 9301, South Africa \\ ${ }^{4}$ Janssen Research \& Development LLC, 1125 Trenton-Harbourton Road, Titusville, NJ 08560-0200, USA \\ ${ }^{5}$ Janssen Infectious Diseases BVBA, Turnhoutseweg 30, 2340 Beerse, Belgium
}

Correspondence should be addressed to Catherine Orrell; catherine.orrell@hiv-research.org.za

Received 11 September 2014; Revised 26 November 2014; Accepted 9 December 2014

Academic Editor: Andrea Mangano

Copyright (c) 2015 Catherine Orrell et al. This is an open access article distributed under the Creative Commons Attribution License, which permits unrestricted use, distribution, and reproduction in any medium, provided the original work is properly cited.

\begin{abstract}
Objectives. TEACH (NCT00896051) was a randomized, open-label, two-arm Phase II trial to investigate the pharmacokinetic interaction between etravirine and atazanavir/ritonavir and safety and efficacy in treatment-experienced, HIV-1-infected patients. Methods. After a two-week lead-in of two nucleoside reverse transcriptase inhibitors (NRTIs) and atazanavir/ritonavir 300/100 mg, 44 patients received etravirine $200 \mathrm{mg}$ bid with one NRTI, plus atazanavir/ritonavir 300/100 $\mathrm{mg}$ or 400/100 mg qd ( $n=22$ each group) over 48 weeks. Results. At steady-state etravirine with atazanavir/ritonavir 300/100 mg qd or 400/100 mg qd decreased atazanavir $C_{\min }$ by $18 \%$ and $9 \%$, respectively, with no change in $\mathrm{AUC}_{24 \mathrm{~h}}$ or $C_{\max }$ versus atazanavir/ritonavir $300 / 100 \mathrm{mg}$ qd alone (Day -1). Etravirine $\mathrm{AUC}_{12 \mathrm{~h}}$ was $24 \%$ higher and $16 \%$ lower with atazanavir/ritonavir $300 / 100$ or $400 / 100 \mathrm{mg}$ qd, respectively, versus historical controls. At Week 48, no significant differences were seen between the atazanavir/ritonavir groups in discontinuations due to adverse events (9.1\% each group) and other safety parameters, the proportion of patients with viral load $<50 \mathrm{copies} / \mathrm{mL}$ (intent-totreat population, noncompleter $=$ failure $)(50.0 \%$, atazanavir/ritonavir $300 / 100 \mathrm{mg}$ qd versus $45.5 \%, 400 / 100 \mathrm{mg}$ qd), and virologic failures (31.8\% versus $27.3 \%$, resp.). Conclusions. Etravirine $200 \mathrm{mg}$ bid can be combined with atazanavir/ritonavir $300 / 100 \mathrm{mg}$ qd and an NRTI in HIV-1-infected, treatment-experienced patients without dose adjustment.
\end{abstract}

\section{Introduction}

It is important to tailor the antiretroviral regimen for a treatment-experienced, HIV-1-infected patient so that it includes at least two (preferably three) fully active agents, based on pretreatment drug resistance testing. Other important considerations for combining antiretrovirals include side effects and drug-drug interactions [1-4].

Etravirine is a nonnucleoside reverse transcriptase inhibitor (NNRTI) for use in combination with other antiretrovirals in treatment-experienced patients with NNRTIresistant HIV-1 virus. The HIV-1 protease inhibitor (PI) atazanavir is most commonly used with low-dose ritonavir in both treatment-naïve and -experienced patients [1-4].

In healthy volunteers who received etravirine $800 \mathrm{mg}$ twice daily (bid) (formulation TF035) and atazanavir/ritonavir 300/100 mg once daily (qd), atazanavir area under the plasma concentration-time curve from time of administration to 24 hours after dosing $\left(\mathrm{AUC}_{24 \mathrm{~h}}\right)$ decreased by $14 \%$ and the minimum plasma concentration $\left(C_{\min }\right)$ decreased by $38 \%$. Etravirine $\mathrm{AUC}_{24} \mathrm{~h}$ and $C_{\min }$ both increased by 1.3 -fold [5]. Although this Phase I study evaluated the $800 \mathrm{mg}$ bid formulation, subsequent assessments demonstrated that 


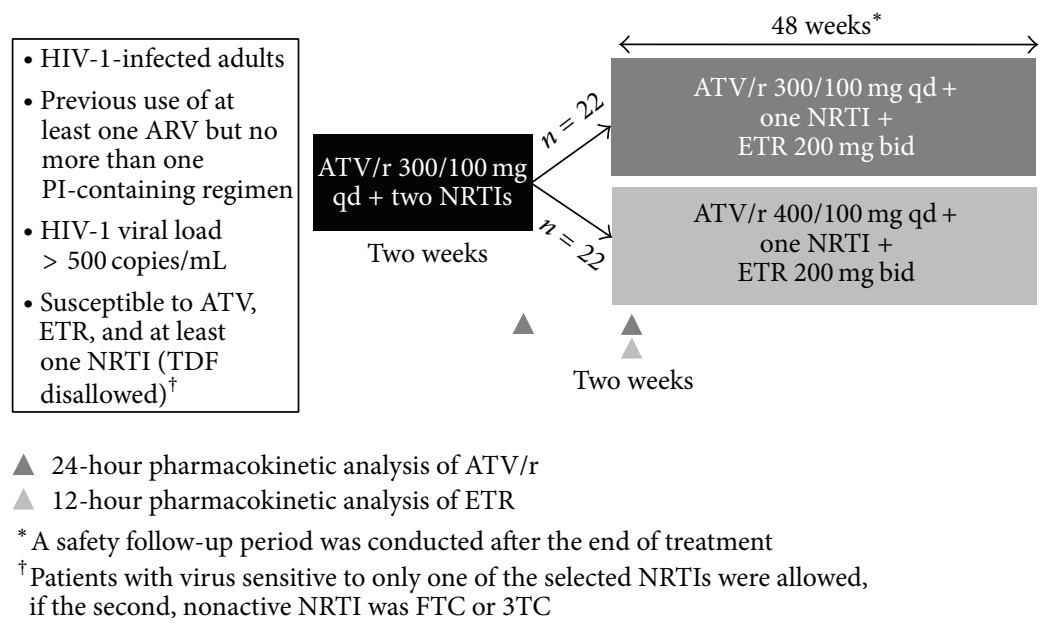

FIGURE 1: TEACH study design. TEACH was an open-label, randomized, exploratory Phase II trial. A two-week pretreatment period was followed by 48 weeks of treatment. 3TC: lamivudine; ARV: antiretroviral; ATV/r: atazanavir/ritonavir; ETR: etravirine; FTC: emtricitabine; NRTI: nucleoside reverse transcriptase inhibitor; PI: protease inhibitor; TDF: tenofovir disoproxil fumarate.

exposure to etravirine was comparable between the commercial $100 \mathrm{mg}$ tablet formulation (F060) when dosed $200 \mathrm{mg}$ bid and the $200 \mathrm{mg}$ formulation (TF035) when dosed $800 \mathrm{mg}$ bid [6].

There is concern that a reduction in $C_{\min }$ for boosted PIs can lower their antiviral activity [7, 8]. However, other studies have not demonstrated a clear relationship between atazanavir $C_{\min }$ and virologic response [9-15], except for a recent study of unboosted atazanavir [16]. In the Phase III DUET trials in which etravirine was combined with darunavir/ritonavir and nucleoside/tide reverse transcriptase inhibitors (N[t]RTIs) [17-20], there was no apparent relationship between etravirine pharmacokinetics and virologic response or safety [21].

TEACH (trial with etravirine and atazanavir/ritonavir combination therapy for HIV infection; TMC125-TiDP2C238; NCT00896051) was an exploratory trial to investigate whether the interaction between etravirine and atazanavir that has been observed in healthy volunteers also occurred in HIV-1-infected, treatment-experienced patients. The Week 2 pharmacokinetic results and final 48-week efficacy and safety analysis are presented.

\section{Methods}

2.1. Patients. The main inclusion criteria were HIV-1-infected adults who had previously received $\geq 1$ antiretroviral regimen but failed $\leq 1$ PI-based regimen and were currently on a stable but failing antiretroviral regimen (viral load [VL] $>500$ copies/mL at screening) (Cobas Amplicor HIV-1 VL assay, Roche Molecular Systems, Inc., Branchburg, NJ, USA; assay performed by Covance Central Laboratory Services). Patients were required to be sensitive to atazanavir, etravirine, and the selected NRTIs (with the exception of emtricitabine or lamivudine) based on resistance testing at screening using the PhenoSense GT assay (Monogram Biosciences, South San Francisco, CA, USA). The assay combines phenotypic test results (PhenoSense HIV) with genotypic results (GeneSeq $\mathrm{HIV}$ ) resulting in a net assessment interpretation on the report per tested drug, that is, resistant, partially sensitive, or sensitive. The clinical cut-offs used for etravirine and boosted atazanavir were 2.9-10.0 and 5.2, respectively. Exclusion criteria included HIV-2 infection, previous failure of $\geq 2$ PI-containing regimens, and presence of $\geq 1$ of the following NNRTI resistance-associated mutations (RAMs): K103R, V106I, I167V, V179D/F/T, Y181I/V, and G190S.

The trial protocol was reviewed and approved by an independent ethics committee and an institutional review board. The trial was carried out in accordance with the principles of Good Clinical Practice and Declaration of Helsinki. Written informed consent was obtained from all patients prior to study start.

2.2. Study Design and Treatment. TEACH was a randomized, open-label, two-arm, 48-week, Phase II trial to evaluate the pharmacokinetics, safety and tolerability, efficacy and virology of etravirine (F060), and atazanavir/ritonavir at two doses, both given with an NRTI over 48 weeks, in treatmentexperienced, HIV-1-infected patients.

The trial consisted of a $\leq 4$-week screening period, a pretreatment period of two weeks (atazanavir/ritonavir 300/100 mg qd and two NRTIs), and a 48-week treatment period. Patients were randomized $1: 1$, by a computer-generated interactive web response system, to receive either atazanavir/ritonavir 300/100 mg qd or $400 / 100 \mathrm{mg}$ qd (Figure 1). Atazanavir/ritonavir was dosed at $300 / 100 \mathrm{mg}$ qd to investigate if the interaction in treatment-experienced patients is consistent with that observed in healthy volunteers [5]. Atazanavir/ritonavir $400 / 100 \mathrm{mg}$ qd was given to the other group to offset the potential reduction in atazanavir exposure, while at the same time investigating if the higher dose of atazanavir might further affect etravirine exposure. At baseline, in both groups, one of the two NRTIs was switched to etravirine $200 \mathrm{mg}$ bid. NRTIs were selected by 
the investigators based on resistance testing; however, tenofovir disoproxil fumarate (TDF) was not permitted. Patients who were intolerant to their NRTI could switch to another sensitive NRTI, excluding TDF. Tenofovir decreases both atazanavir [22] and etravirine [23] exposure. These decreases do not significantly affect exposure of either drug, but an additive effect could result in reduced clinical efficacy when given in combination, particularly since etravirine also reduces atazanavir/ritonavir exposure. As such, a substudy to assess the addition of TDF for seven days on atazanavir and etravirine pharmacokinetics was conducted in patients with $>24$ weeks of treatment and who had $\geq 2$ consecutive VL values $<50$ copies $/ \mathrm{mL}$.

2.3. Study Objectives and Assessments. The primary objective of TEACH was to evaluate the pharmacokinetic interaction between etravirine and atazanavir/ritonavir at two different doses over 48 weeks. Secondary objectives included evaluation of safety and tolerability, antiviral activity, changes in $\mathrm{CD}^{+}$cell count, and viral genotype and phenotype.

Blood samples for analyses of atazanavir and ritonavir plasma concentrations were collected over 24 hours (before dose and $1,2,3,4,6,9,12$, and 24 hours after dose) on the last day of the two-week pretreatment period and after Week 2 of the treatment period. Blood samples for evaluation of etravirine plasma concentrations were collected after Week 2. Atazanavir, ritonavir, and etravirine [24, 25] were assayed using validated liquid chromatography-mass spectrometry/mass spectrometry, with a lower limit of quantification of $250 \mathrm{ng} / \mathrm{mL}, 5.00 \mathrm{ng} / \mathrm{mL}$, and $2.00 \mathrm{ng} / \mathrm{mL}$, respectively.

Adverse events (AEs; division of AIDS grading [26]), laboratory parameters (serum clinical chemistry, hematology, and urinalysis), and 12-lead electrocardiograms (ECGs) were recorded throughout the study.

During the treatment session, plasma VL was determined at baseline, Weeks 2 and 4, and monthly until Week 48 . Virologic failures were classified as patients who were still in the study at Week 12 and (i) who never achieved two consecutive VL values $<50$ copies $/ \mathrm{mL}$ (nonresponders) or (ii) first achieved two consecutive VL values $<50$ copies $/ \mathrm{mL}$ followed by two consecutive VL values $>50$ copies $/ \mathrm{mL}$ or discontinued for any reason with $\mathrm{VL}>50$ copies $/ \mathrm{mL}$ (rebounders). Changes in viral phenotype and genotype in virologic failures were determined using the PhenoSense GT assay.

2.4. Data Analyses. Pharmacokinetic parameters were obtained using noncompartmental analysis (WinNonlin Professional version 4.1, Pharsight, Mountain View, CA, USA) and included $C_{\min }$, maximum plasma concentration $\left(C_{\max }\right)$, and $\mathrm{AUC}_{12 \mathrm{~h}}$ for etravirine and $\mathrm{AUC}_{24 \mathrm{~h}}$ for atazanavir and ritonavir.

Statistical analysis was performed for atazanavir/ritonavir $300 / 100 \mathrm{mg} \mathrm{qd}$ or $400 / 100 \mathrm{mg}$ qd with etravirine at Week 2 (test) versus atazanavir/ritonavir $300 / 100 \mathrm{mg} \mathrm{qd}$ without etravirine on the last day of the two-week pretreatment period (reference), including all observations for test and reference, paired and unpaired. The least square means (LSM) of $C_{\min }$, $C_{\max }$, and $\mathrm{AUC}_{24}$ for atazanavir and ritonavir were estimated with a linear mixed-effects model, including treatment as fixed effect and subject as a random effect (SAS version 9.3, SAS Institute, Cary, NC, USA). A 90\% confidence interval (CI) was constructed around the difference between the LSM of test and reference. The LSM differences and 90\% CIs were retransformed to the original scale. No effect (prespecified) was declared if the $90 \%$ CIs of the LSM ratio were within the limits of $80.00-125.00 \%$. The pharmacokinetics of etravirine was compared with historic data from DUET [21].

Based on the atazanavir $C_{\min }$ variability in HIV-infected patients receiving atazanavir/ritonavir $300 / 100 \mathrm{mg} \mathrm{qd}, 19$ evaluable patients per dose group were required to provide sufficient precision for the estimated $C_{\min }$ LSM ratio ( $90 \%$ CI within $20 \%$ of the estimate). Four additional patients per group were included to cover for early dropouts.

Safety analyses were conducted on the safety intent-totreat (ITT) population, consisting of all patients who had taken at least one dose of trial medication (etravirine or atazanavir/ritonavir) (i.e., started the pretreatment session). QT intervals were corrected for heart rate according to Fridericia (QTcF).

Efficacy analyses were conducted on the efficacy ITT population, consisting of all patients who had taken at least one dose of etravirine during the trial (i.e., started the treatment session). The primary efficacy endpoint was virologic response at Week 48 (proportion of patients with VL < 50 copies $/ \mathrm{mL}$ ). For discontinuations, subsequent timepoints were imputed with baseline values (noncompleter status equals failure $[\mathrm{NC}=\mathrm{F}]$ ); intermediate missing values were imputed using last observation carried forward. Based on a logistic regression model with prebaseline plasma VL as covariate and treatment as factor, the predicted proportion of responders (with 95\% CI) for each dose group was calculated. In addition, an ANCOVA model was used to analyze changes in plasma VL from prebaseline. Mean (standard error) change from prebaseline in $\mathrm{CD}^{+}$cell count $(\mathrm{NC}=\mathrm{F})$ was calculated.

\section{Results}

3.1. Patient Disposition and Baseline Characteristics. Seventeen investigators in four countries (Argentina, South Africa, Thailand and the USA) participated.

Of the 143 screened patients, 50 were enrolled and treated with atazanavir/ritonavir 300/100 mg qd plus two NRTIs in the pretreatment session (Figure 2) (three patients were not treated). Of the 90 screening failures, the majority were due to $\mathrm{VL} \leq 500$ copies $/ \mathrm{mL}$ at screening $(n=37)$, lack of sensitivity to etravirine, atazanavir and $\geq 1$ NRTI $(n=19)$, and absence of $\geq 1$ NNRTI RAM $(n=17)$. Six patients discontinued (Figure 2) and 44 patients continued into the 48-week treatment session $(n=22$ in each atazanavir dose group). Thirty-one patients (62\%) completed the study, with 13 patients discontinuing for noncompliance $(n=4)$, AEs $(n=3)$, loss to follow-up $(n=3)$, withdrawal of consent $(n=1)$, and other reasons $(n=2)$. 


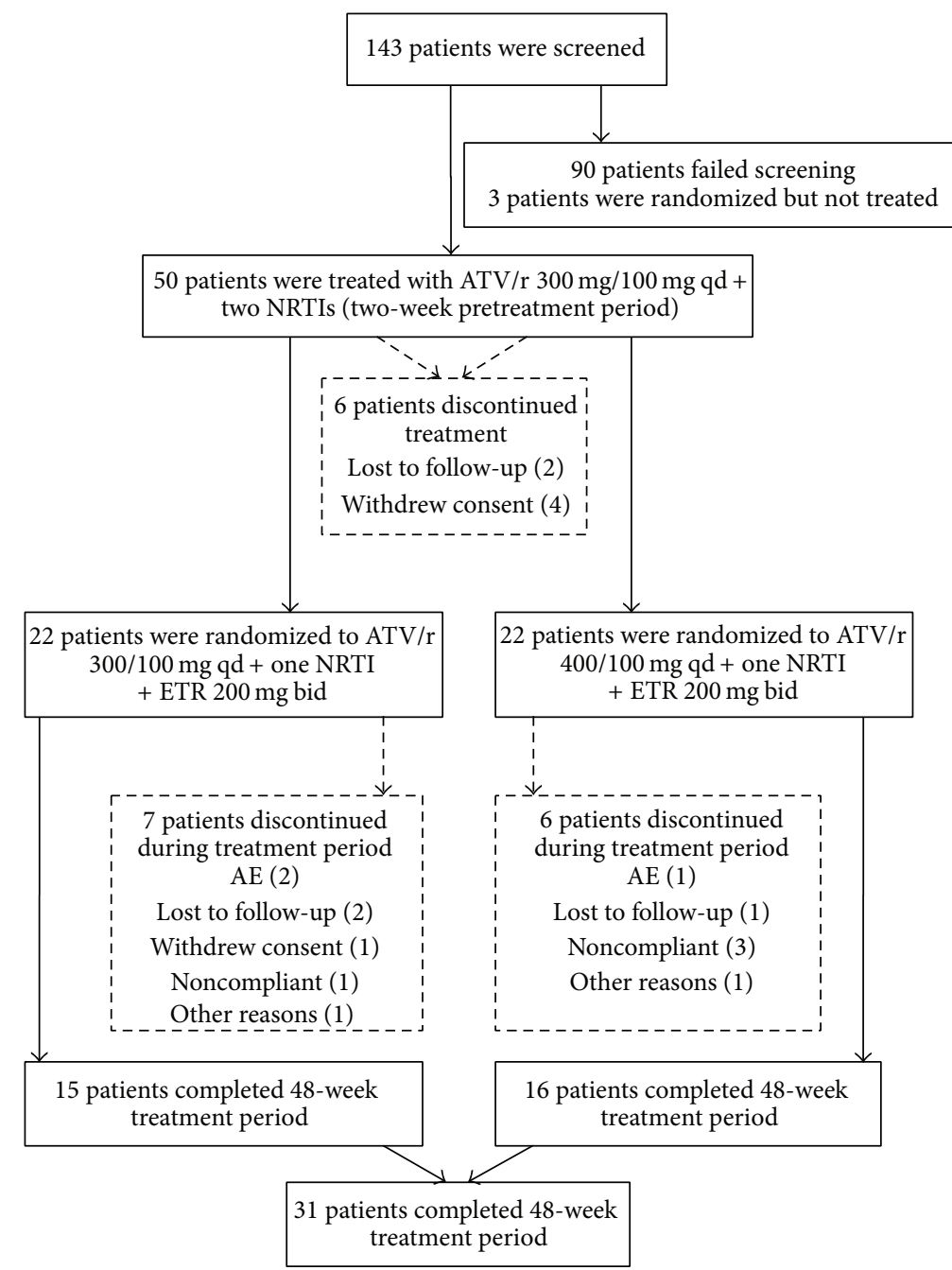

FIGURE 2: Patient disposition. AE: adverse event; ATV/r: atazanavir/ritonavir; ETR: etravirine; NRTI: nucleoside reverse transcriptase inhibitor.

Baseline characteristics were generally balanced between treatment groups. There were, however, more Black/AfricanAmerican patients and more patients from South Africa but fewer Asian patients in the atazanavir/ritonavir 400/ $100 \mathrm{mg}$ qd group than in the atazanavir/ritonavir 300/ $100 \mathrm{mg}$ qd group (Table 1). Of the patients with data available, most patients who continued into the treatment period had $\geq 2$ NNRTI RAMs (81\% [34/42]) [27] and $\geq 1$ IAS-USA NRTI RAM (90.5\% [38/42]) [28] but no IAS-USA primary PI mutations $(88.1 \%$ [37/42]) at baseline [28].

3.2. Prior and Concomitant Antiretroviral Use. Most patients (90.9\% [40/44]) entering the 48-week treatment session had previously received $\geq 1$ NNRTI. All patients had previously received $\geq 2$ NRTIs, and $34.1 \%$ of patients (15/44) had previously received a PI. During the 48 -week treatment session, the most frequently used NRTIs were stavudine $(36.4 \%$ [16/44]) and zidovudine (31.8\% [14/44]). Use of NRTIs was similar between treatment groups.
3.3. Pharmacokinetics. With atazanavir/ritonavir 300/ $100 \mathrm{mg}$ qd, mean atazanavir plasma concentrations in the presence of etravirine (Week 2) were similar to the mean concentrations with atazanavir/ritonavir $300 / 100 \mathrm{mg} \mathrm{qd}$ alone (Day -1) over the first 4 hours but were slightly lower in the presence versus absence of etravirine from 4 to 24 hours (Figure 3(a)). Coadministration of etravirine with atazanavir/ritonavir $300 / 100 \mathrm{mg}$ qd decreased atazanavir $C_{\text {min }}$ by $18 \%$ (Table 2 ) and $C_{\max }$ and $\mathrm{AUC}_{24 \mathrm{~h}}$ were relatively unchanged (Table 2) compared with atazanavir/ritonavir 300/100 mg qd alone.

With atazanavir/ritonavir 400/100 $\mathrm{mg}$ qd, mean atazanavir plasma concentrations in the presence of etravirine (Week 2) were similar to mean concentrations with atazanavir/ ritonavir 300/100 $\mathrm{mg}$ qd alone (Day -1) across the dosing interval (Figure 3(b)). Etravirine coadministration decreased atazanavir $C_{\min }$ by $9 \%$, and $C_{\max }$ and $\mathrm{AUC}_{24 \mathrm{~h}}$ were relatively unchanged (Table 2) versus atazanavir/ritonavir 300/ $100 \mathrm{mg}$ qd alone. 
TABLE 1: Patient baseline demographics and disease characteristics of patients who started the pretreatment session.

\begin{tabular}{|c|c|c|c|}
\hline & $\begin{array}{c}\text { Atazanavir/ritonavir } \\
300 / 100 \mathrm{mg} \mathrm{qd}+\text { one NRTI + } \\
\text { etravirine } 200 \mathrm{mg} \text { bid }(n=25)\end{array}$ & $\begin{array}{c}\text { Atazanavir/ritonavir } \\
400 / 100 \mathrm{mg} \mathrm{qd}+\text { one NRTI }+ \\
\text { etravirine } 200 \mathrm{mg} \text { bid }(n=25)\end{array}$ & $\begin{array}{l}\text { All patients } \\
\quad(n=50)\end{array}$ \\
\hline Female $[n(\%)]$ & $12(48.0)$ & $13(52.0)$ & $25(50.0)$ \\
\hline Age, years [median (range)] & $39.0(26-63)$ & $40.0(18-56)$ & $40.0(18-63)$ \\
\hline \multicolumn{4}{|l|}{$\operatorname{Race}[n(\%)]$} \\
\hline Black or African-American & $12(48.0)$ & $18(72.0)$ & $30(60.0)$ \\
\hline Asian & $6(24.0)$ & $2(8.0)$ & $8(16.0)$ \\
\hline White & $6(24.0)$ & $5(20.0)$ & $11(22.0)$ \\
\hline Others & $1(4.0)$ & 0 & $1(2.0)$ \\
\hline \multicolumn{4}{|l|}{ Country $[n(\%)]$} \\
\hline South Africa & $9(36.0)$ & $13(52.0)$ & $22(44.0)$ \\
\hline USA & $10(40.0)$ & $8(32.0)$ & $18(36.0)$ \\
\hline Thailand & $6(24.0)$ & $2(8.0)$ & $8(16.0)$ \\
\hline Argentina & 0 & $2(8.0)$ & $2(4.0)$ \\
\hline Prebaseline $\log _{10}$ VL (copies/mL) [median (range)] & $4.1(2-6)$ & $4.1(2-6)$ & $4.1(2-6)$ \\
\hline Prebaseline $\mathrm{CD} 4^{+}$cell count, median (range), cells $/ \mathrm{mm}^{3}$ & $186(8-678)$ & $238(55-1061)$ & $223(8-1061)$ \\
\hline Duration of HIV infection, years (median (range)) & $7.2(2-16)$ & $6.7(1-26)$ & $7.0(1-26)$ \\
\hline \multicolumn{4}{|l|}{ CDC clinical stage of infection $[n(\%)]$} \\
\hline A & $10(40.0)$ & $9(36.0)$ & $19(38.0)$ \\
\hline $\mathrm{B}$ & $7(28.0)$ & $7(28.0)$ & $14(28.0)$ \\
\hline $\mathrm{C}$ & $8(32.0)$ & $9(36.0)$ & $17(34.0)$ \\
\hline \multicolumn{4}{|l|}{ Mode of HIV infection $[n(\%)]$} \\
\hline Heterosexual contact & $15(60.0)$ & $12(48.0)$ & $27(54.0)$ \\
\hline Heterosexual contact/MSM & $1(4.0)$ & $1(4.0)$ & $2(4.0)$ \\
\hline MSM & $5(20.0)$ & $5(20.0)$ & $10(20.0)$ \\
\hline Others & $4(16.0)$ & $7(28.0)$ & $11(22.0)$ \\
\hline
\end{tabular}

CDC: Centers for Disease Control and Prevention; MSM: men who have sex with men; $n$ : number of patients per treatment group; $n$ (\%): number (proportion) of patients with specified parameter; NRTI: nucleoside reverse transcriptase inhibitor; VL: viral load. Prebaseline: Day 1 of the pretreatment period.

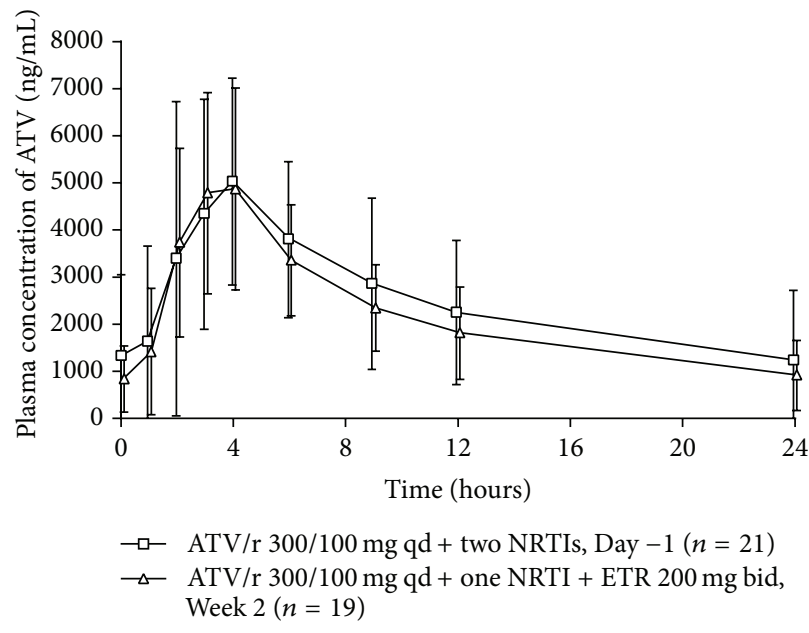

(a)

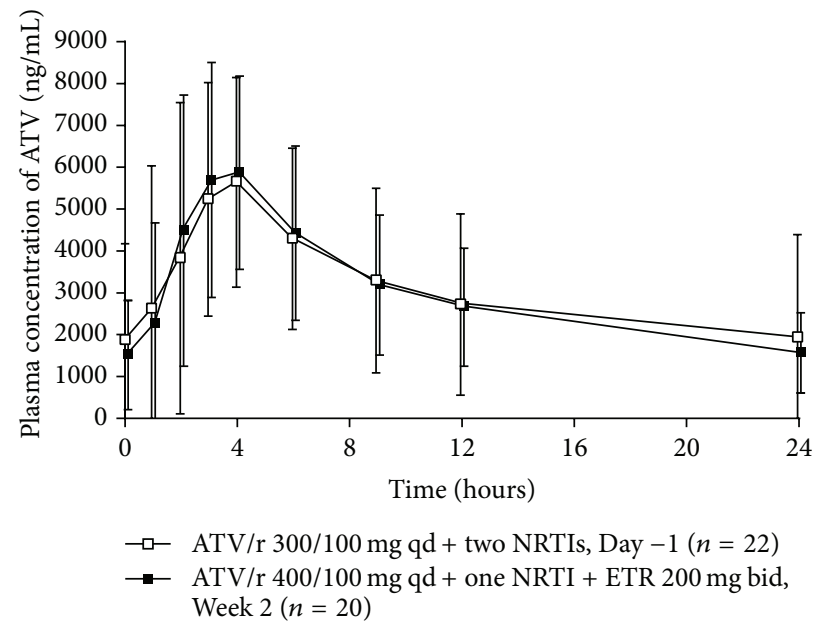

(b)

FIGURE 3: Mean \pm standard deviation atazanavir plasma concentration-time curves after administration of atazanavir/ritonavir $300 / 100 \mathrm{mg}$ qd for two weeks in combination with two NRTIs (Day -1), followed by administration of etravirine 200 mg bid for two weeks in combination with one NRTI and (a) atazanavir/ritonavir 300/100 mg qd or (b) atazanavir/ritonavir 400/100 mg qd (Week 2). ATV/r: atazanavir/ritonavir; bid: twice daily; ETR: etravirine; NRTI: nucleoside reverse transcriptase inhibitor; qd: once daily. 
TABLE 2: Pharmacokinetic parameters and statistical analysis of atazanavir after administration of atazanavir/ritonavir $300 / 100 \mathrm{mg} q d$ for two weeks in combination with two NRTIs (Day -1), followed by administration of etravirine $200 \mathrm{mg}$ bid for two weeks in combination with one NRTI and atazanavir/ritonavir 300/100 mg qd or atazanavir/ritonavir 400/100 mg qd (Week 2).

\begin{tabular}{|c|c|c|c|c|}
\hline \multirow[b]{2}{*}{$\begin{array}{l}\text { Pharmacokinetics of } \\
\text { atazanavir mean } \pm \\
\mathrm{SD} ; t_{\max }: \text { median } \\
\text { (range) }\end{array}$} & \multicolumn{2}{|c|}{ Group one } & \multicolumn{2}{|c|}{ Group two } \\
\hline & $\begin{array}{c}\mathrm{ATV} / \mathrm{r} 300 / 100 \mathrm{mg} \text { qd } \\
+ \text { two NRTIs } \\
\text { (reference) } \\
\left(n=20^{*}\right)\end{array}$ & $\begin{array}{l}\text { ATV/r 300/100 mg qd } \\
+ \text { one NRTI + ETR } \\
200 \text { mg bid (Test } 1) \\
\left(n=18^{\dagger}\right)\end{array}$ & $\begin{array}{c}\mathrm{ATV} / \mathrm{r} 300 / 100 \mathrm{mg} \text { qd } \\
+ \text { two NRTIs } \\
\text { (reference) } \\
\left(n=21^{\ddagger}\right)\end{array}$ & $\begin{array}{l}\text { ATV/r 400/100 mg qd } \\
+ \text { one NRTI + ETR } \\
200 \mathrm{mg} \text { bid (Test 2) } \\
\left(n=20^{\S}\right)\end{array}$ \\
\hline$C_{0 \mathrm{~h}}, \mathrm{ng} / \mathrm{mL}$ & $1339 \pm 1728$ & $845.7 \pm 703.3$ & $1898 \pm 2298$ & $1545 \pm 1296$ \\
\hline$C_{\min }, \mathrm{ng} / \mathrm{mL}$ & $1104 \pm 1511$ & $758.6 \pm 610.5$ & $1671 \pm 2310$ & $1107 \pm 866.8$ \\
\hline$C_{\max }, \mathrm{ng} / \mathrm{mL}$ & $5652 \pm 2735$ & $5232 \pm 2166$ & $6419 \pm 2853$ & $6950 \pm 2693$ \\
\hline$t_{\max }, \mathrm{h}$ & $4.00(1.98-6.00)$ & $3.00(1.00-4.17)$ & $3.04(1.00-6.00)$ & $3.21(1.25-6.17)$ \\
\hline $\mathrm{AUC}_{0-24 \mathrm{~h}}, \mathrm{ng} \cdot \mathrm{h} / \mathrm{mL}$ & $60030 \pm 39690$ & $55070 \pm 21860$ & $74210 \pm 55480$ & $72220 \pm 34600$ \\
\hline \multicolumn{5}{|l|}{$\begin{array}{l}\text { LSM ratio }(90 \% \mathrm{CI}) \text { of } \\
\text { test versus reference }\end{array}$} \\
\hline$C_{\min }$ & \multicolumn{2}{|c|}{$0.82(0.55-1.22)$} & \multicolumn{2}{|c|}{$0.91(0.63-1.33)$} \\
\hline$C_{\max }$ & \multicolumn{2}{|c|}{$0.96(0.80-1.16)$} & \multicolumn{2}{|c|}{$1.05(0.86-1.27)$} \\
\hline $\mathrm{AUC}_{0-24 \mathrm{~h}}$ & \multicolumn{2}{|c|}{$0.96(0.76-1.22)$} & \multicolumn{2}{|c|}{$0.99(0.81-1.21)$} \\
\hline
\end{tabular}

ATV/r: atazanavir/ritonavir; $\mathrm{AUC}_{0-24 \mathrm{~h}}$ : area under the plasma concentration-time curve from time 0 to 24 hours; bid: twice daily; CI: confidence interval; $C_{\max }$ : maximum plasma concentration; $C_{\min }$ : minimum plasma concentration; $C_{0 \mathrm{~h}}$ : predose plasma concentration; ETR: etravirine; LSM: least square mean; NRTI: nucleoside reverse transcriptase inhibitor; qd: once daily; SD: standard deviation; $t_{\max }$ : time to maximum plasma concentration.

${ }^{*} n=21$ for $C_{0 \mathrm{~h}}, n=19$ for $\mathrm{AUC}_{24 \mathrm{~h}} ;{ }^{\dagger} n=19$ for $C_{0 \mathrm{~h}}, C_{\max }$, and $T_{\max } ;{ }^{\ddagger} n=22$ for $C_{0 \mathrm{~h}}, C_{\max }$, and $t_{\max } ;{ }^{\circledR} n=18$ for $C_{\min }, n=19$ for AUC $24 \mathrm{~h} ;{ }^{9} \mathrm{calculated}$ based on log-transformed pharmacokinetic parameters.

TABLE 3: Pharmacokinetic parameters and statistical analysis of etravirine after administration of etravirine $200 \mathrm{mg}$ bid for two weeks in combination with atazanavir/ritonavir $300 / 100 \mathrm{mg}$ qd or $400 / 100 \mathrm{mg}$ qd and one NRTI and from the pooled DUET pharmacokinetic substudies at Week 4 [21].

\begin{tabular}{|c|c|c|c|}
\hline $\begin{array}{l}\text { Pharmacokinetics of ETR mean } \\
\pm \mathrm{SD} ; t_{\max }: \text { median (range) }\end{array}$ & $\begin{array}{l}\text { Pooled DUET [21]: ETR } \\
200 \mathrm{mg} \mathrm{bid}+\mathrm{DRV} / \mathrm{r} \\
600 / 100 \mathrm{mg} \text { bid, Week } 4 \\
\text { (reference) } \\
(n=25) \\
\end{array}$ & $\begin{array}{c}\mathrm{ATV} / \mathrm{r} 300 / 100 \mathrm{mg} \mathrm{qd} \\
\text { + one NRTI + ETR } 200 \mathrm{mg} \text { bid, } \\
\text { Week } 2(\text { Test } 1) \\
\left(n=18^{*}\right)\end{array}$ & $\begin{array}{c}\text { ATV } / \mathrm{r} 400 / 100 \mathrm{mg} \mathrm{qd} \\
+ \text { one NRTI + ETR } 200 \mathrm{mg} \text { bid, } \\
\text { Week } 2(\text { Test } 2) \\
\left(n=18^{\dagger}\right)\end{array}$ \\
\hline$C_{0 h}, n g / m L$ & $545.0 \pm 818.6$ & $422.2 \pm 327.9$ & $316.6 \pm 215.4$ \\
\hline$C_{\min }, \mathrm{ng} / \mathrm{mL}$ & $452.6 \pm 806.0$ & $425.1 \pm 328.1$ & $286.5 \pm 198.0$ \\
\hline$C_{\max }, \mathrm{ng} / \mathrm{mL}$ & $879.6 \pm 1030$ & $773.0 \pm 360.5$ & $628.7 \pm 294.0$ \\
\hline$t_{\max }, \mathrm{h}$ & $3.95(0.08-6.08)$ & $4.00(3.00-9.00)$ & $4.00(2.00-6.07)$ \\
\hline $\mathrm{AUC}_{0-12 \mathrm{~h}}, \mathrm{ng} \cdot \mathrm{h} / \mathrm{mL}$ & $7964 \pm 11180$ & $7629 \pm 4213$ & $5171 \pm 2695$ \\
\hline
\end{tabular}

LSM ratio $(90 \% \mathrm{CI})$ of test versus reference ${ }^{\ddagger}$

\begin{tabular}{llcc}
\hline & & Test 1 versus reference & Test 2 versus reference \\
\hline$C_{\min }$ & - & $1.07(0.60-1.90)$ & $0.83(0.54-1.29)$ \\
$C_{\max }$ & - & $1.06(0.78-1.46)$ & $0.87(0.65-1.18)$ \\
$\mathrm{AUC}_{0-12 \mathrm{~h}}$ & - & $1.24(0.88-1.76)$ & $0.84(0.60-1.18)$ \\
\hline
\end{tabular}

$\mathrm{ATV} / \mathrm{r}$ : atazanavir/ritonavir; $\mathrm{AUC}_{0-12 \mathrm{~h}}$ : area under the plasma concentration-time curve from time 0 to 12 hours; bid: twice daily; CI: confidence interval; $C_{\max }$ : maximum plasma concentration; $C_{\min }$ : minimum plasma concentration; $C_{0 \mathrm{~h}}$ : predose plasma concentration; ETR: etravirine; LSM: least square mean; NRTI: nucleoside reverse transcriptase inhibitor; qd: once daily; SD: standard deviation; $t_{\max }$ : time to maximum plasma concentration.

${ }^{*} n=19$ for $C_{0 \mathrm{~h}}, n=16$ for $C_{\min }, n=17$ for $\mathrm{AUC}_{0-12 \mathrm{~h}},{ }^{\dagger} n=19$ for $C_{0 \mathrm{~h}}$, and $n=20$ for $C_{\max }$ and $t_{\max }{ }^{*}{ }^{*}$ calculated based on log-transformed pharmacokinetic parameters.

Mean etravirine plasma concentrations were higher in the atazanavir/ritonavir $300 / 100 \mathrm{mg}$ qd group than in the atazanavir/ritonavir 400/100 mg qd group, across the dosing interval (Figure 4). Compared with historic control data [21], coadministration of atazanavir/ritonavir $300 / 100 \mathrm{mg} \mathrm{qd}$ with etravirine resulted in $7 \%, 6 \%$, and $24 \%$ increases in etravirine $C_{\min }, C_{\max }$, and $\mathrm{AUC}_{12 \mathrm{~h}}$, respectively (Table 3). With atazanavir/ritonavir $400 / 100 \mathrm{mg} \mathrm{qd}$, there were $17 \%$, $13 \%$, and $16 \%$ decreases in etravirine $C_{\min }, C_{\max }$, and $\mathrm{AUC}_{12 \mathrm{~h}}$, respectively, compared with historic data (Table 3).

Seven patients participated in the pharmacokinetic substudy, 3 patients randomized to atazanavir/ritonavir 


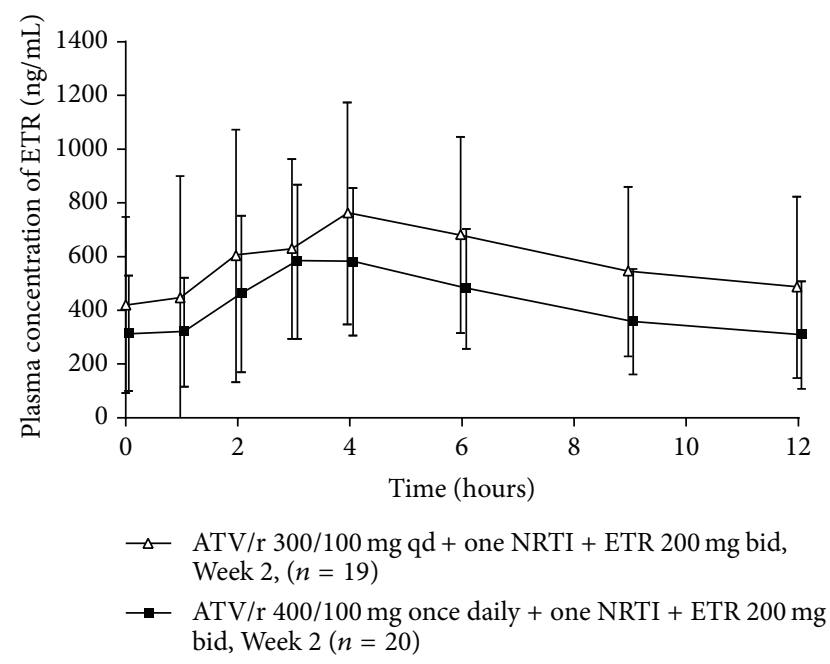

FIgURE 4: Mean \pm standard deviation etravirine plasma concentration-time curves after administration of etravirine $200 \mathrm{mg}$ bid for two weeks in combination with atazanavir/ritonavir $300 / 100 \mathrm{mg}$ qd or 400/100 mg qd and one NRTI. ATV/r: atazanavir/ritonavir; bid: twice daily; ETR: etravirine; NRTI: nucleoside reverse transcriptase inhibitor; qd: once daily.

$300 / 100 \mathrm{mg} q \mathrm{qd}$ and 4 patients randomized to atazanavir/ ritonavir 400/100 $\mathrm{mg} \mathrm{qd}$. Because of the small sample size, results of the two groups were combined. Adding TDF to atazanavir/ritonavir and etravirine decreased atazanavir $C_{\min }$ by $25 \%$ (LSM ratio [90\% CIs]: $0.75[0.41-1.36]), C_{\max }$ by $3 \%(0.97[0.75-1.25])$, and $\mathrm{AUC}_{24 \mathrm{~h}}$ by $9 \%(0.91[0.72-1.13])$ and decreased etravirine $C_{\max }$ by $19 \%(0.81$ [0.72-0.91]) and $\mathrm{AUC}_{12 \mathrm{~h}}$ by $15 \%$ (0.85 [0.79-0.92]), compared with Day -1 . Etravirine $C_{\min }$ was relatively unchanged in the presence of TDF (LSM ratio [90\% CI]: 0.97 [0.85-1.10]).

3.4. Safety and Tolerability. During the 48-week treatment session, safety and tolerability were comparable between the two treatment groups (Table 4). The most common AEs were cough, headache, influenza, and sinusitis (Table 4). Each of the AEs considered at least possibly related to etravirine (not including laboratory abnormalities reported as an AE), that is, pruritus, rash, dyspepsia, nausea, hyperuricemia, goitre, edema, and headache, occurred in no more than one patient overall.

The majority of AEs were Grade 1 or 2 in severity. Each Grade 3 or $4 \mathrm{AE}$ or serious $\mathrm{AE}$ was reported in only one patient, except for pneumonia, which occurred in one patient in each treatment group. Grade $4 \mathrm{AEs}$ were reported in three patients in the atazanavir/ritonavir $300 / 100 \mathrm{mg}$ qd group, only one of which (hyperuricemia) was considered possibly related to etravirine.

No serious AEs were considered related to etravirine. One death occurred in the atazanavir/ritonavir 300/100 mg qd group (Table 4) as a result of metastatic malignant melanoma (considered not related to etravirine). Except for an increase in direct, indirect, and total bilirubin values during the pretreatment period, which remained elevated throughout

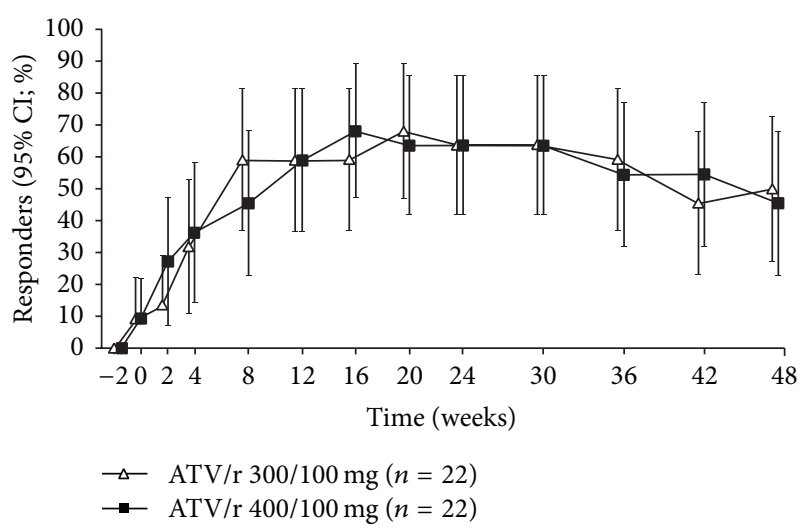

FIGURE 5: Virologic response (viral load $(\mathrm{VL})<50$ copies $/ \mathrm{mL}$ ) over time to Week 48 (intent-to-treat noncompleter equals failure: $\mathrm{NC}=\mathrm{F}$ ). $\mathrm{NC}=\mathrm{F}$ missing values after discontinuation imputed with change $=0$. Last observation was carried forward otherwise. ATV $/ \mathrm{r}$ : atazanavir/ritonavir; CI: confidence interval; VL: viral load.

the Week 48 treatment period, mean changes over time in clinical laboratory parameters were generally small in both treatment groups and not considered clinically relevant. No clinically relevant mean changes from baseline were seen in vital signs or ECG parameters. No patients had a QTcF interval $\geq 480 \mathrm{~ms}$.

3.5. Antiviral Activity and Development of Resistance. Virologic response $(\mathrm{VL}<50$ copies $/ \mathrm{mL}$; ITT, $\mathrm{NC}=\mathrm{F})$ was achieved in $50 \%$ (95\% CI: $28.2-71.8 \%$ ) of patients in the atazanavir/ritonavir $300 / 100 \mathrm{mg}$ qd group and $45.5 \%(95 \%$ CI: $24.4-67.8 \%)$ in the atazanavir/ritonavir $400 / 100 \mathrm{mg} \mathrm{qd}$ group (Table 5). At Week 48, there was no difference in virologic response between the two treatment groups when adjusted for prebaseline VL $(P=0.692$; logistic regression) or in the mean change in $\log _{10}$ plasma VL from prebaseline $(P=0.845$; ANCOVA). The snapshot analysis results and the $\mathrm{NC}=\mathrm{F}$ analysis results were similar (Table 5). In the snapshot analysis, five patients (11.4\%) had discontinued the study by Week 48 for reasons not related to safety or efficacy and with the last available $\mathrm{VL}<50$ copies $/ \mathrm{mL}$. In both treatment groups, the virologic response $(\mathrm{NC}=\mathrm{F})$ increased from prebaseline (Week -2) to Week 20, remained stable until Week 30, and decreased slowly from Week 30 to 48 (Figure 5).

Week 48 virologic failure rates were comparable between treatment groups $(31.8 \%$ [7/22] in the atazanavir/ritonavir $300 / 100 \mathrm{mg}$ qd group and $27.3 \%$ [6/22] in the atazanavir/ ritonavir 400/100 mg qd group (four nonresponders and nine rebounders)).

In the 13 virologic failures, nine NNRTI RAMs emerged at endpoint (V90I, K101P, E138G, Y181C, V189I, G190S, H221Y, $\mathrm{P} 225 \mathrm{H}$, and M230L). Seven of these RAMs occurred in one patient each, whereas K101P developed in two patients and Y181C emerged in three patients. Median etravirine weighted genotypic score $(n=13)$ increased from 0 (range: $0-3)$ at baseline to $2.5(0-4.5)$ at endpoint and median etravirine FC $(n=12)$ increased from $0.73(0.4-1.7)$ to $2.99(0.6-$ 40.0), whereas no increase in atazanavir FC was observed, 
TABLE 4: Overview of AEs and laboratory abnormalities during the 48-week treatment session.

\begin{tabular}{|c|c|c|c|}
\hline Incidence, $(n(\%))$ & $\begin{array}{c}\text { Atazanavir/ritonavir } \\
300 / 100 \mathrm{mg} \mathrm{qd}+\text { one NRTI + } \\
\text { etravirine } 200 \mathrm{mg} \text { bid }(n=22)\end{array}$ & $\begin{array}{c}\text { Atazanavir/ritonavir } \\
400 / 100 \mathrm{mg} \mathrm{qd}+\text { one NRTI }+ \\
\text { etravirine } 200 \mathrm{mg} \text { bid }(n=22)\end{array}$ & All patients $(n=44)$ \\
\hline Any AE & $20(90.9)$ & $17(77.3)$ & $37(84.1)$ \\
\hline Any treatment-related $\mathrm{AE}$ & $5(22.7)$ & $5(22.7)$ & $10(22.7)$ \\
\hline Grade 3-4 AEs & $4(18.2)$ & $4(18.2)$ & $8(18.2)$ \\
\hline AEs leading to discontinuation & $2^{*}(9.1)$ & $2^{\dagger}(9.1)$ & $4(9.1)$ \\
\hline Serious AEs & $4(18.2)$ & $2(9.1)$ & $6(13.6)$ \\
\hline Death & $1(4.5)$ & 0 & $1(2.3)$ \\
\hline \multicolumn{4}{|c|}{ AEs regardless of relationship to study treatment and occurring in $\geq 3$ patients ${ }^{\ddagger}$} \\
\hline Cough & $5(22.7)$ & $4(18.2)$ & $9(20.5)$ \\
\hline Headache & $3(13.6)$ & $4(18.2)$ & $7(15.9)$ \\
\hline Influenza & $2(9.1)$ & $3(13.6)$ & $5(11.4)$ \\
\hline Sinusitis & $3(13.6)$ & 0 & $3(6.8)$ \\
\hline \multicolumn{4}{|c|}{${ }^{\S} \mathrm{AEs}$ of interest regardless of relationship to study treatment, occurring in $\geq 2$ patients } \\
\hline Hepatotoxicity & $5(22.7)$ & $5(22.7)$ & $5(22.7)$ \\
\hline Rash (any type) & $3(13.6)$ & $2(9.1)$ & $5(11.4)$ \\
\hline Neuropsychiatric AEs & $3(13.6)$ & 0 & $3(6.8)$ \\
\hline \multicolumn{4}{|c|}{ Treatment-emergent Grade 2-4 laboratory abnormalities occurring in $\geq 2$ patients } \\
\hline & $n=21$ & $n=21$ & $n=42^{¥}$ \\
\hline Hyperbilirubinemia & $8(38.1)$ & $6(28.6)$ & $14(33.3)$ \\
\hline Increased total cholesterol & $3(14.3)$ & $3(14.3)$ & $6(14.3)$ \\
\hline Increased LDL-cholesterol & $1(4.8)$ & $5(23.8)$ & $6(14.3)$ \\
\hline Hyperglycemia & $4(19.0)$ & $1(4.8)$ & $5(11.9)$ \\
\hline Increased pancreatic amylase & $1(4.8)$ & $3(14.3)$ & $4(9.5)$ \\
\hline Increased segmented neutrophils & $2(9.5)$ & $2(9.5)$ & $4(9.5)$ \\
\hline Increased hemoglobin & $1(4.8)$ & $1(4.8)$ & $2(4.8)$ \\
\hline Increased white blood cell count & $2(9.5)$ & 0 & $2(4.8)$ \\
\hline Increased AST & $1(4.8)$ & $1(4.8)$ & $2(4.8)$ \\
\hline
\end{tabular}

AE: adverse event; AST: aspartate amino transferase; LDL: low-density lipoprotein; $n$ : number of patients per treatment group; $n$ (\%): number (proportion) of patients with specified parameter; NRTI: nucleoside reverse transcriptase inhibitor.

${ }^{*}$ One patient died (metastatic malignant melanoma), and one experienced Grade 2 maculopapular rash probably related to etravirine and atazanavir and discontinued treatment on the day of onset (eight days after the start of etravirine treatment).

${ }^{\dagger}$ One patient discontinued at Week 48 due to Grade 2 secondary syphilis considered not related to study medication. Another patient became pregnant and discontinued the study.

${ }^{\ddagger}$ Not including laboratory abnormalities reported as an AE.

${ }^{\S}$ AEs of special interest were selected based on their association with other antiretrovirals and relevance based on preclinical or earlier clinical data and the target population. Hepatotoxicity was considered at least possibly related to atazanavir for five and four patients in the atazanavir/ritonavir $300 / 100 \mathrm{mg}$ qd and $400 / 100 \mathrm{mg}$ qd treatment groups, respectively and at least possibly related to etravirine in three patients. Neuropsychiatric AEs of interest, including Grade 2 depression in one patient and Grade 2 peripheral neuropathy in two patients, were considered not serious and not related to etravirine and did not lead to discontinuation.

Grouped term including rash (not further specified), maculopapular rash and papular rash.

${ }^{¥}$ Two patients did not have post-dose laboratory data because they discontinued shortly after baseline.

and the NRTIs used remained sensitive. Emerging atazanavir RAMs [27] were only observed in the atazanavir/ritonavir 300/100 mg qd group: L10F $(n=1)$, V32I $(n=1)$, M46I $(n=$ $2)$, and V82A $(n=1)$. No primary PI mutations associated with resistance to atazanavir emerged at endpoint.

3.6. Immunologic Response. An increase in $\mathrm{CD} 4^{+}$cell count from prebaseline was observed at all timepoints in both treatment groups. There was no significant difference $(P=$ 0.714; ANCOVA) in the mean increase from prebaseline in absolute $\mathrm{CD} 4^{+}$count $(\mathrm{NC}=\mathrm{F})$ at Week 48 between treatment groups (Table 5).

\section{Discussion}

In HIV-1-infected patients who have failed virologically with demonstrated RAMs on an antiretroviral regimen, treatment options for the new regimen include a fully active PI/r and classes not used previously, for example, a fusion or integrase inhibitor, CCR5 antagonist (R5 virus only), or an 
TABLE 5: Virologic and immunologic outcomes at Week 48.

\begin{tabular}{|c|c|c|c|}
\hline Week 48 outcomes & $\begin{array}{c}\text { Atazanavir/ritonavir } \\
\text { 300/100 mg qd + one NRTI } \\
\text { + etravirine } \\
200 \mathrm{mg} \text { bid }(n=22)\end{array}$ & $\begin{array}{l}\text { Atazanavir/ritonavir } \\
400 / 100 \mathrm{mg} \mathrm{qd}+\text { one NRTI } \\
+ \text { etravirine } 200 \mathrm{mg} \text { bid } \\
(n=22)\end{array}$ & All patients $(n=44)$ \\
\hline \multicolumn{4}{|l|}{ ITT, $\mathrm{NC}=\mathrm{F}$} \\
\hline${ }^{*} \mathrm{VL}<50$ copies/mL, $n(\%)$ & $11(50.0)$ & $10(45.5)$ & $21(47.7)$ \\
\hline $\mathrm{VL}<400$ copies $/ \mathrm{mL}, n(\%)$ & $11(50.0)$ & $13(59.1)$ & $24(54.5)$ \\
\hline $\begin{array}{l}{ }^{\dagger} \log _{10} V L \text {, mean }(\mathrm{SE}) \text { change from prebaseline } \\
(\text { Week }-2)\end{array}$ & $-1.4(0.24)$ & $-1.4(0.29)$ & $-1.4(0.18)$ \\
\hline $\begin{array}{l}{ }^{*} \text { Increase from prebaseline in absolute } \mathrm{CD} 4^{+} \text {count, } \\
\text { cells } / \mathrm{mm}^{3}(\text { mean }(\mathrm{SE}))(\mathrm{NC}=\mathrm{F})\end{array}$ & $105(31.1)$ & $132(32.6)$ & $118(22.3)$ \\
\hline \multicolumn{4}{|l|}{ Snapshot } \\
\hline $\mathrm{VL}<50$ copies $/ \mathrm{mL}[n(\%)]$ & $11(50.0)$ & $10(45.5)$ & $21(47.7)$ \\
\hline
\end{tabular}

${ }^{*} P=0.692$, logistic regression; ${ }^{\dagger} P=0.845$, ANCOVA; and ${ }^{\ddagger} P=0.714$, ANCOVA for comparison between the two treatment groups, corrected for baseline VL and baseline $\mathrm{CD} 4^{+}$count respectively.

ITT: intent-to-treat; $n$ : number of patients per treatment group; $n$ (\%): number (proportion) of patients with observations; $\mathrm{NC}=\mathrm{F}$ : noncompleter equals failure (missing values after discontinuation imputed with change $=0$; last observation was carried forward otherwise); NRTI: nucleoside reverse transcriptase inhibitor; SE: standard error; VL: viral load.

NNRTI such as etravirine, based on genotypic drug resistance testing. As such, the TEACH study sought to investigate the interaction between etravirine and atazanavir/ritonavir at two different doses in treatment-experienced, HIV-1infected patients. We showed that etravirine $200 \mathrm{mg}$ bid can be combined with atazanavir/ritonavir 300/100 mg qd and an NRTI in a treatment regimen for HIV-1-infected, treatmentexperienced patients without dose adjustment.

An earlier drug-drug interaction study showed a marked decrease in atazanavir exposure when given with etravirine [5]. The current study, in treatment-experienced, HIV-1infected patients, appeared to result in a smaller effect on atazanavir than observed in healthy volunteers [5]. The cause of this is unknown but may be related to differences in metabolic activity between healthy volunteers and HIVinfected patients. For example, CYP3A activity in HIVinfected patients is half of that observed in healthy volunteers; P-glycoprotein activity is also lower [29]. It could also be due to differences in the etravirine formulation (TF035 versus F060) as the commercial formulation F060 is more bioavailable [6]. An interaction study with etravirine administered as either of the two formulations and TDF, however, showed no significant difference between the two formulations [23]. Increasing the atazanavir/ritonavir dose from 300/100 to $400 / 100 \mathrm{mg}$ qd resulted in a less than proportional increase in atazanavir exposure. However, a comparison between atazanavir/ritonavir dose groups of the changes in atazanavir pharmacokinetics in the presence of etravirine should be interpreted with caution as atazanavir exhibits nonlinear disposition [30].

The effect of atazanavir/ritonavir $300 / 100 \mathrm{mg} \mathrm{qd}$ on etravirine exposure in HIV-infected patients was also less than anticipated based on previous results in healthy volunteers [5]. Increasing the dose of atazanavir/ritonavir to $400 / 100 \mathrm{mg}$ qd further reduced etravirine exposure. This observation should be interpreted with caution because the 95\% CIs of the LSM ratios were wide and the effect of increasing the dose of atazanavir/ritonavir to $400 / 100 \mathrm{mg}$ qd is based on a comparison between groups.

There were no clinically significant differences in safety between the two treatment groups. Following coadministration of etravirine and atazanavir/ritonavir, the majority of AEs were Grade 1 or 2 . No new safety findings were observed compared with the known safety profiles of etravirine and atazanavir.

The virologic response rate was not significantly different between the atazanavir/ritonavir 300/100 mg qd and $400 / 100 \mathrm{mg}$ qd groups. While the approved atazanavir/ritonavir dose in treatment-experienced adults is $300 / 100 \mathrm{mg}$ qd [1-4], similar responses have been observed with atazanavir/ ritonavir $300 / 100 \mathrm{mg}$ qd and atazanavir $400 \mathrm{mg}$ qd in treatment-naive patients $[31,32]$. In the current study, patients were highly treatment experienced, with $81 \%$ having $\geq 2$ NNRTI RAMs at baseline. Virologic response was lower in this study than in Phase III DUET trials at Week 48, where a response of $57 \%$ was observed in treatment-experienced adults receiving etravirine combined with darunavir/ritonavir and $\mathrm{N}[\mathrm{t}] \mathrm{RTIs}$ and reusing or not using enfuvirtide [1720]. However, virologic response in the current study was influenced by a relatively high proportion of discontinuations of patients with undetectable VL (in relation to a small total sample size) for reasons not related to safety or efficacy. Nonetheless, the observed response rates are in line with other studies in similar populations of highly treatmentexperienced patients [33-35].

The only NNRTI RAMs emerging at endpoint in $\geq 1$ patient experiencing virologic failure were K101P and Y181C, which were both previously defined as etravirine RAMs [36]. No relevant development of resistance to atazanavir occurred.

The main limitation of the study is that it was an exploratory Phase II study. Since the study was powered to evaluate the pharmacokinetic interaction between etravirine and atazanavir/ritonavir rather than to compare virologic outcomes between the two different atazanavir doses, 
the safety and efficacy findings should be interpreted with caution, noting the small numbers of patients in each treatment group. A second limitation is the large number of patients who discontinued the study, influencing the results. However, these discontinuations were mainly attributed to reasons other than AEs such as nonadherence, loss to followup, and withdrawal of consent.

A third limitation was that TDF was not permitted; therefore, the effect on efficacy due to its interactions with atazanavir [22] and etravirine [23], if TDF was to be coadministered with these agents, is not known. In the substudy, while addition of TDF to atazanavir/ritonavir and etravirine resulted in a modest decrease in the exposure of atazanavir and etravirine, this result should be interpreted with caution given the small number of patients.

In summary, there was a smaller pharmacokinetic interaction between etravirine and atazanavir/ritonavir in HIVinfected patients than what was observed previously in healthy volunteers [5]. Increasing the atazanavir dose to $400 \mathrm{mg}$ did not substantially increase atazanavir exposure but decreased etravirine exposure. Etravirine $200 \mathrm{mg}$ bid can be combined with atazanavir/ritonavir 300/100 mg qd and an NRTI, in a treatment regimen for HIV-1-infected, treatmentexperienced patients without dose adjustment.

\section{Disclosure}

Thomas N. Kakuda, Ludo Lavrey, Steven Nijs, Lotke Tambuyzer, Rodica Van Solingen-Ristea, and Frank L. Tomaka are full time employees of Janssen. Catherine Orrell has received funding from Janssen to attend the IAC conference in Malaysia in July 2013 and present the 48-week TEACH analysis poster (conference registration, travel, accommodation, and meals), and Franco Felizarta has been a speaker for Janssen, Merck, Vertex, and ViiV Healthcare and has undertook research with AbbVie, Boehringer Ingelheim, Gilead, Janssen, Merck, Vertex, and ViiV Healthcare.

\section{Conflict of Interests}

André Nell declares no conflict of interests.

\section{Authors' Contribution}

Catherine Orrell, Franco Felizarta, and André Nell all participated in recruiting significant numbers of patients to the trials and reported data for those patients. Thomas N. Kakuda, Ludo Lavrey, Steven Nijs, Lotke Tambuyzer, Rodica Van Solingen-Ristea, and Frank L. Tomaka all had a significant involvement in the data analyses. All authors were involved in the development of the primary paper and interpretation of data, have read and approved the final version, and have met the criteria for authorship as established by the ICMJE.

\section{Acknowledgments}

The authors would like to thank the patients and their families, investigators, study center staff and Janssen study personnel, in particular Johan Verspeelt and Magda Opsomer, and
David Anderson, Blanca Hadacek, and Eric Wong for their input into this paper. This study was sponsored/supported by Janssen Pharmaceuticals, Ireland. Medical writing support was provided by Ian Woolveridge of Gardiner-Caldwell Communications, Macclesfield, UK, part of KnowledgePoint360, an Ashfield Company; this support was funded by Janssen Pharmaceuticals. Portions of these data have been previously presented at the 13th International Workshop on Clinical Pharmacology of HIV Therapy (Barcelona, Spain, 16-18 April 2012. Abstract O_24) and at the 7th International AIDS Society Conference on HIV Pathogenesis, Treatment and Prevention (IAC; Kuala Lumpur, Malaysia, 30 June-3 July 2013. Abstract WEPE519).

\section{References}

[1] "DHHS guidelines, Panel on Antiretroviral Guidelines for Adults and Adolescents. Guidelines for the use of antiretroviral agents in HIV-1-infected adults and adolescents," Department of Health and Human Services, 2014, http://aidsinfo.nih.gov/ contentfiles/lvguidelines/adultandadolescentgl.pdf.

[2] H. F. Günthard, J. A. Aberg, J. J. Eron et al., "International Antiviral Society-USA Panel. Antiretroviral treatment of adult HIV infection: 2014 recommendations of the International Antiviral Society-USA Panel," The Journal of the American Medical Association, vol. 312, no. 4, pp. 410-425, 2014.

[3] BHIVA, "British HIV Association guidelines for the treatment of HIV-1-positive adults with antiretroviral therapy 2012 (Updated November 2013. All changed text is cast in yellow highlight.)," HIV Medicine, vol. 15, supplement 1, pp. 1-85, 2014.

[4] EACS, "European Guidelines for treatment of HIV infected adults in Europe," Version 7.1, 2014, http://www.eacsociety.org/ Portals/0/140601 EACS\%20EN7.02.pdf.

[5] M. Schöller-Gyüre, B. Woodfall, T. De Marez et al., "Pharmacokinetics of TMC125 with atazanavir and atazanavir/ritonavir," in Proceedings of the 8th International Congress on Drug Therapy in HIV Infection, Poster P278, Glasgow, UK, November 2006.

[6] T. N. Kakuda, M. Schöller-Gyüre, C. Workman et al., "Singleand multiple-dose pharmacokinetics of etravirine administered as two different formulations in HIV-1-infected patients," Antiviral Therapy, vol. 13, no. 5, pp. 655-661, 2008.

[7] D. González de Requena, O. Gallego, L. Valer, I. JiménezNácher, and V. Soriano, "Prediction of virological response to lopinavir/ritonavir using the genotypic inhibitory quotient," AIDS Research and Human Retroviruses, vol. 20, no. 3, pp. 275278, 2004.

[8] H. Wu, Y. Huang, E. P. Acosta et al., "Pharmacodynamics of antiretroviral agents in HIV-1 infected patients: using viral dynamic models that incorporate drug susceptibility and adherence," Journal of Pharmacokinetics and Pharmacodynamics, vol. 33, no. 4, pp. 399-419, 2006.

[9] A. Barrios, A. L. Rendón, O. Gallego et al., "Predictors of virological response to Atazanavir in protease inhibitorexperienced patients," HIV Clinical Trials, vol. 5, no. 4, pp. 201205, 2004.

[10] A. Winston, M. Bloch, A. Carr et al., "Atazanavir trough plasma concentration monitoring in a cohort of HIV-1-positive individuals receiving highly active antiretroviral therapy," Journal of Antimicrobial Chemotherapy, vol. 56, no. 2, pp. 380-387, 2005. 
[11] N. Gianotti, E. Seminari, M. Guffanti et al., "Evaluation of atazanavir Ctrough, atazanavir genotypic inhibitory quotient, and baseline HIV genotype as predictors of a 24-week virological response in highly drug-experienced, HIV-infected patients treated with unboosted atazanavir," New Microbiologica, vol. 28, no. 2, pp. 119-125, 2005.

[12] I. Pellegrin, D. Breilh, J.-M. Ragnaud et al., "Virological responses to atazanavir-ritonavir-based regimens: resistancesubstitutions score and pharmacokinetic parameters (Reyaphar study)," Antiviral Therapy, vol. 11, no. 4, pp. 421-429, 2006.

[13] R. M. M. Cleijsen, M. E. Van de ende, F. P. Kroon et al., "Therapeutic drug monitoring of the HIV protease inhibitor atazanavir in clinical practice," Journal of Antimicrobial Chemotherapy, vol. 60, no. 4, pp. 897-900, 2007.

[14] C. Solas, P. Colson, I. Ravaux et al., "The genotypic inhibitory quotient: a predictive factor of atazanavir response in HIV-1infected treatment-experienced patients," Journal of Acquired Immune Deficiency Syndromes, vol. 48, no. 2, pp. 177-180, 2008.

[15] R. J. Bertz, A. Persson, E. Chung et al., "Pharmacokinetics and pharmacodynamics of atazanavir-containing antiretroviral regimens, with or without ritonavir, in patients who are HIVpositive and treatment-naïve," Pharmacotherapy, vol. 33, no. 3, pp. 284-294, 2013.

[16] S. Goutell, T. Baudry, M.-C. Gagnieu et al., "Pharmacokineticpharmacodynamic modeling of unboosted atazanavir in a cohort of stable HIV-infected patients," Antimicrobial Agents and Chemotherapy, vol. 57, no. 1, pp. 517-523, 2013.

[17] J. V. Madruga, P. Cahn, B. Grinsztejn et al., "Efficacy and safety of TMC125 (etravirine) in treatment-experienced HIV1-infected patients in DUET-1: 24-week results from a randomised, double-blind, placebo-controlled trial," The Lancet, vol. 370, no. 9581, pp. 29-38, 2007.

[18] A. Lazzarin, T. Campbell, B. Clotet et al., "Efficacy and safety of TMC125 (etravirine) in treatment-experienced HIV-1-infected patients in DUET-2: 24-week results from a randomised, double-blind, placebo-controlled trial," The Lancet, vol. 370, no. 9581, pp. 39-48, 2007.

[19] C. Katlama, R. Haubrich, J. Lalezari et al., "Efficacy and safety of etravirine in treatment-experienced, HIV-1 patients: pooled 48 week analysis of two randomized, controlled trials," AIDS, vol. 23, no. 17, pp. 2289-2300, 2009.

[20] C. Katlama, B. Clotet, A. Mills et al., "Efficacy and safety of etravirine at week 96 in treatment-experienced HIV type-1infected patients in the DUET-1 and DUET-2 trials," Antiviral Therapy, vol. 15, no. 7, pp. 1045-1052, 2010.

[21] T. N. Kakuda, J. R. Wade, E. Snoeck et al., "Pharmacokinetics and pharmacodynamics of the non-nucleoside reversetranscriptase inhibitor etravirine in treatment-experienced HIV-1-infected patients," Clinical Pharmacology and Therapeutics, vol. 88, no. 5, pp. 695-703, 2010.

[22] A.-M. Taburet, C. Piketty, C. Chazallon et al., "Interactions between atazanavir-ritonavir and tenofovir in heavily pretreated human immunodeficiency virus-infected patients," Antimicrobial Agents and Chemotherapy, vol. 48, no. 6, pp. 20912096, 2004.

[23] T. N. Kakuda, M. Schöller-Gyüre, G. De Smedt et al., "Assessment of the steady-state pharmacokinetic interaction between etravirine administered as two different formulations and tenofovir disoproxil fumarate in healthy volunteers," HIV Medicine, vol. 10, no. 3, pp. 173-181, 2009.
[24] M. Schöller-Gyüre, T. N. Kakuda, V. Sekar et al., "Pharmacokinetics of darunavir/ritonavir and TMC125 alone and coadministered in HIV-negative volunteers," Antiviral Therapy, vol. 12, no. 5, pp. 789-796, 2007.

[25] V. J. Sekar, E. Lefebvre, T. de Marez et al., "Pharmacokinetics of darunavir (TMC114) and atazanavir during coadministration in HIV-negative, healthy volunteers," Drugs in $R \& D$, vol. 8, no. 4, pp. 241-248, 2007.

[26] NIAID, "Division of AIDS table for grading the severity of adult and pediatric adverse events-version 1," 2004, http://rsc.techres.com/Document/safetyandpharmacovigilance/Table_for Grading_Severity_of_Adult_Pediatric_Adverse_Events.pdf.

[27] L. Tambuyzer, H. Azijn, L. T. Rimsky et al., "Compilation and prevalence of mutations associated with resistance to nonnucleoside reverse transcriptase inhibitors," Antiviral Therapy, vol. 14, no. 1, pp. 103-109, 2009.

[28] V. A. Johnson, V. Calvez, H. F. Günthard et al., "2011 update of the drug resistance mutations in HIV-1," Topics in Antiviral Medicine, vol. 19, no. 4, pp. 156-164, 2011.

[29] A. Jetter, G. Fätkenheuer, D. Frank et al., "Do activities of cytochrome P450 (CYP)3A, CYP2D6 and P-glycoprotein differ between healthy volunteers and HIV-infected patients?" Antiviral Therapy, vol. 15, no. 7, pp. 975-983, 2010.

[30] L. Dickinson, M. Boffito, D. Back et al., "Population pharmacokinetics of ritonavir-boosted atazanavir in HIV-infected patients and healthy volunteers," Journal of Antimicrobial Chemotherapy, vol. 63, no. 6, pp. 1233-1243, 2009.

[31] D. R. Malan, E. Krantz, N. David, V. Wirtz, J. Hammond, and D. McGrath, "Efficacy and safety of atazanavir, with or without ritonavir, as part of once-daily highly active antiretroviral therapy regimens in antiretroviral-naive patients," Journal of Acquired Immune Deficiency Syndromes, vol. 47, no. 2, pp. 161$167,2008$.

[32] D. R. Malan, E. Krantz, N. David et al., "96-week efficacy and safety of atazanavir, with and without ritonavir, in a HAART regimen in treatment-naive patients," Journal of the International Association of Physicians in AIDS Care, vol. 9, no. 1, pp. 34-42, 2010

[33] M. Johnson, B. Grinsztejn, C. Rodriguez et al., "Atazanavir plus ritonavir or saquinavir, and lopinavir/ritonavir in patients experiencing multiple virological failures," AIDS, vol. 19, no. 7, pp. 685-694, 2005.

[34] C. Cohen, L. Nieto-Cisneros, C. Zala et al., "Comparison of atazanavir with lopinavir/ritonavir in patients with prior protease inhibitor failure: a randomized multinational trial," Current Medical Research and Opinion, vol. 21, no. 10, pp. 16831692,2005

[35] R. Zajdenverg, T. J. Podsadecki, S. Badal-Faesen et al., "Similar safety and efficacy of once-and twice-daily lopinavir/ritonavir tablets in treatment-experienced HIV-1-infected subjects at 48 weeks," Journal of Acquired Immune Deficiency Syndromes, vol. 54, no. 2, pp. 143-151, 2010.

[36] J. Vingerhoets, L. Tambuyzer, H. Azijn et al., "Resistance profile of etravirine: combined analysis of baseline genotypic and phenotypic data from the randomized, controlled Phase III clinical studies," AIDS, vol. 24, no. 4, pp. 503-514, 2010. 


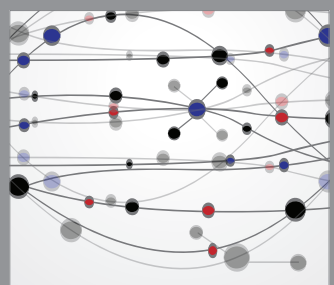

The Scientific World Journal
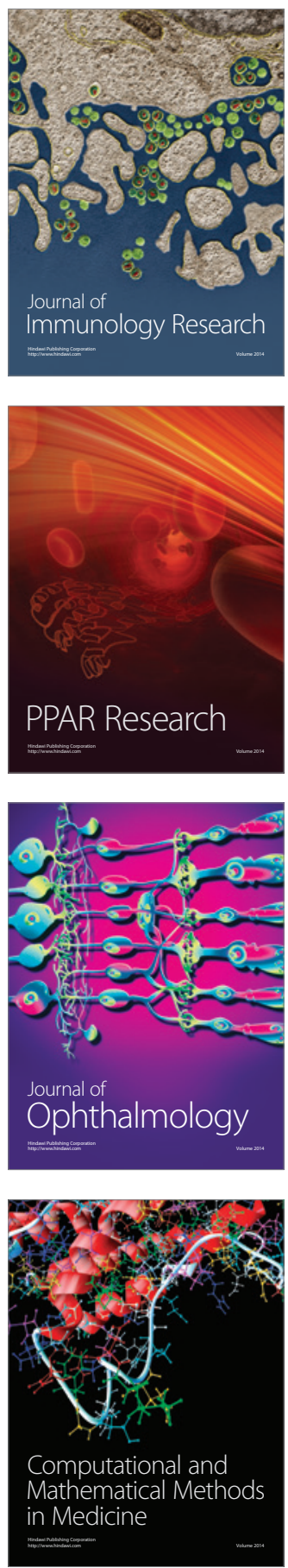

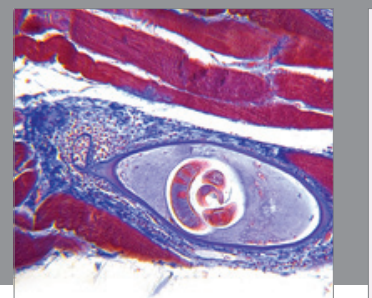

Gastroenterology

Research and Practice
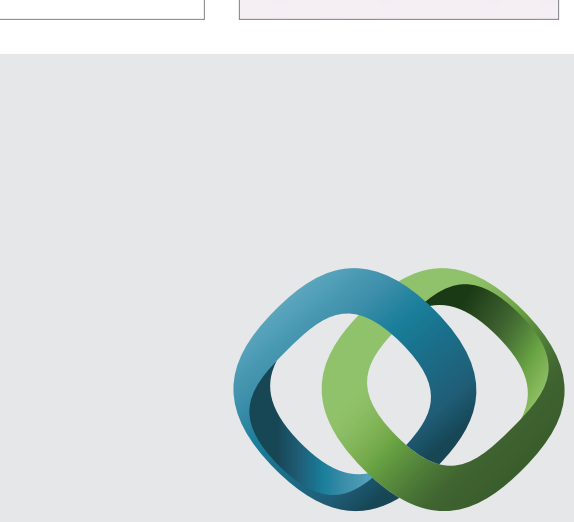

\section{Hindawi}

Submit your manuscripts at

http://www.hindawi.com
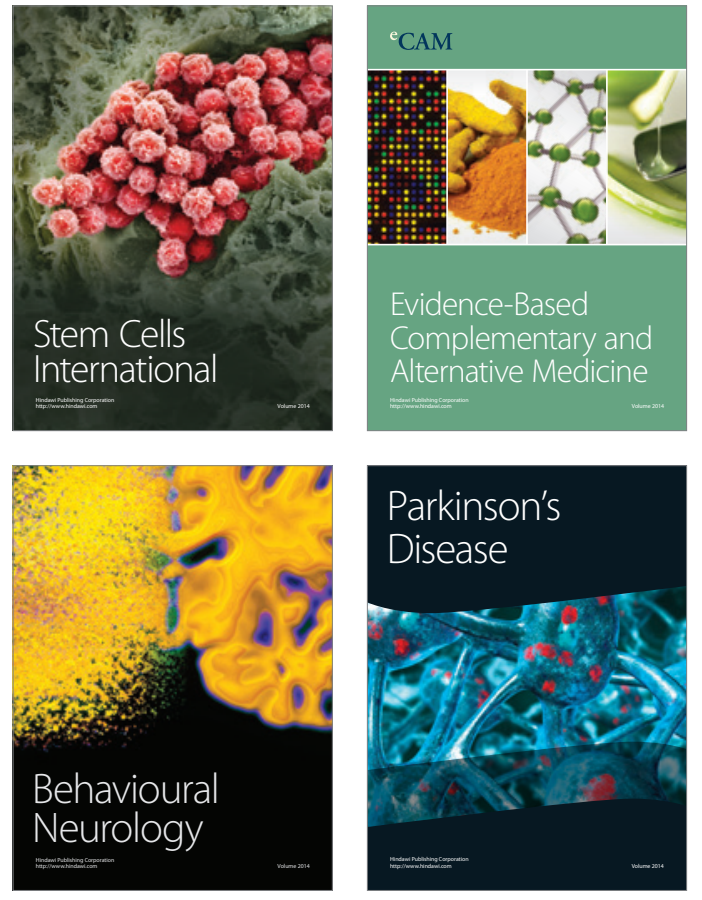
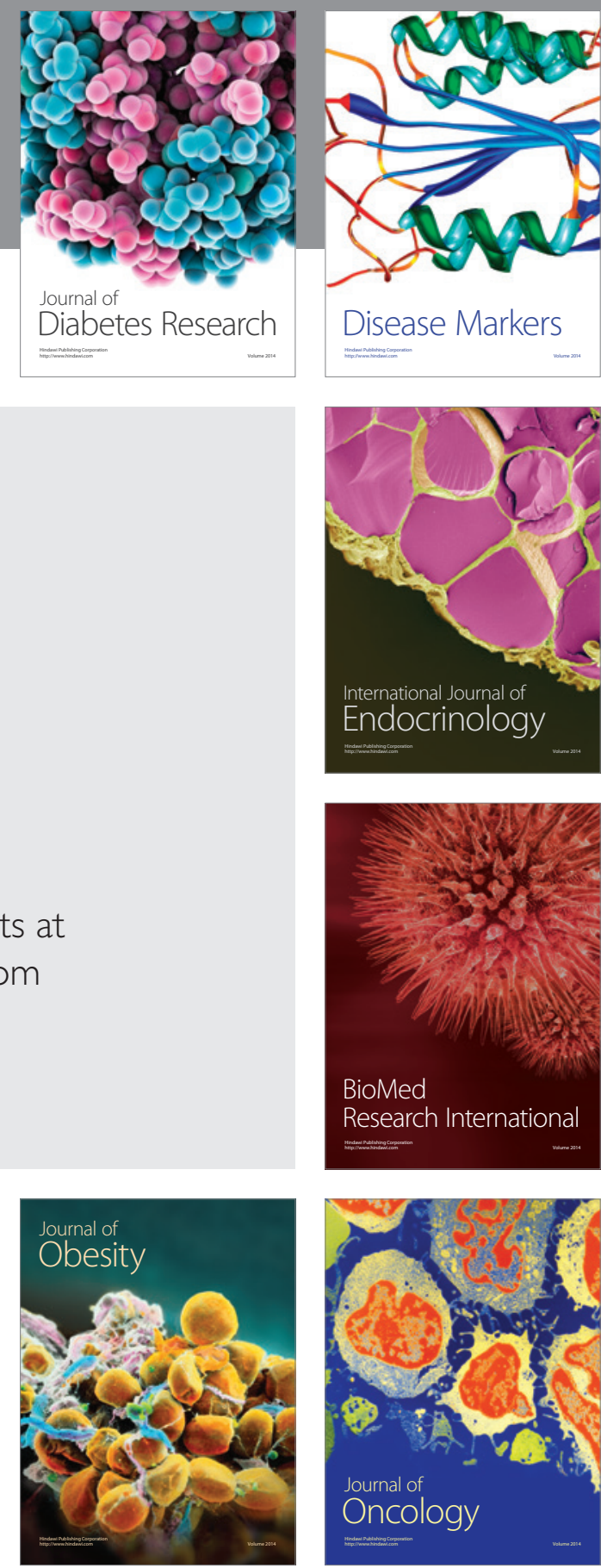

Disease Markers
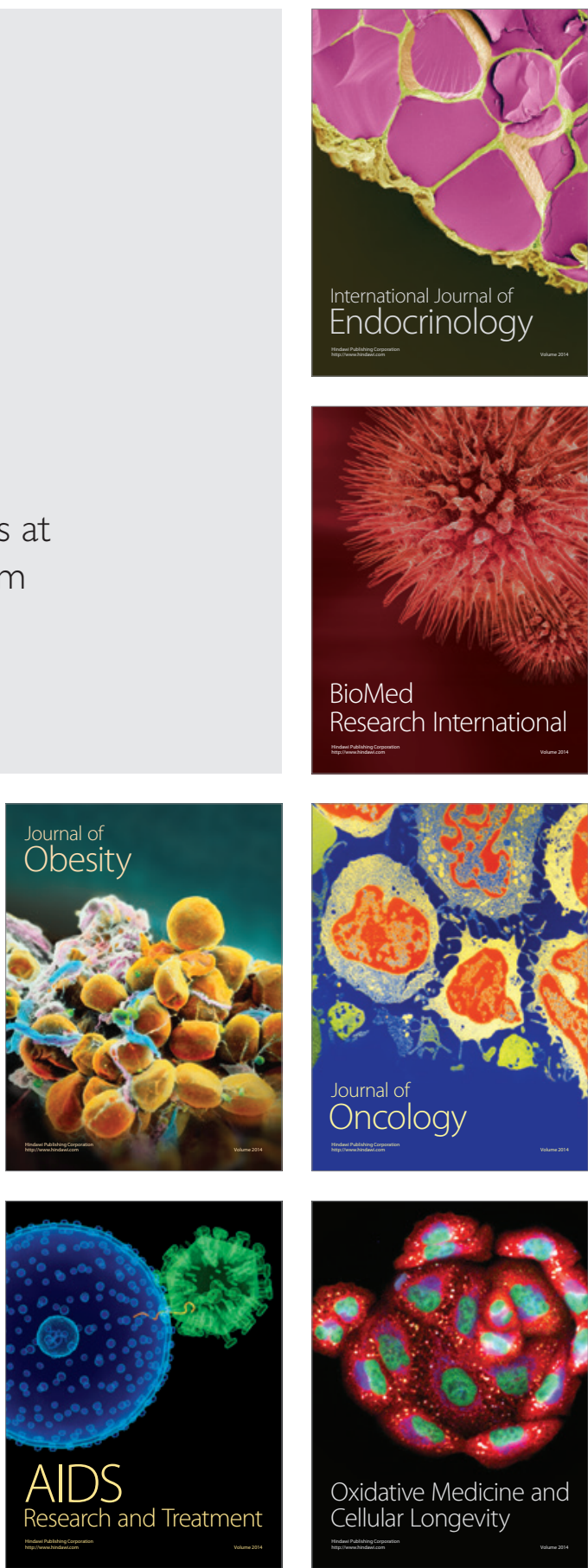